Western University

Scholarship@Western

Department of Economics Research Reports

Economics Working Papers Archive

1992

\title{
Cross-Border Externalities and Trade Liberalization: The Strategic Control of Pollution
}

Rodney D. Ludema

Ian Wooton

Follow this and additional works at: https://ir.lib.uwo.ca/economicsresrpt

Part of the Economics Commons

Citation of this paper:

Ludema, Rodney D., Ian Wooton. "Cross-Border Externalities and Trade Liberalization: The Strategic Control of Pollution."

Department of Economics Research Reports, 9202. London, ON: Department of Economics, University of Western Ontario (1992). 


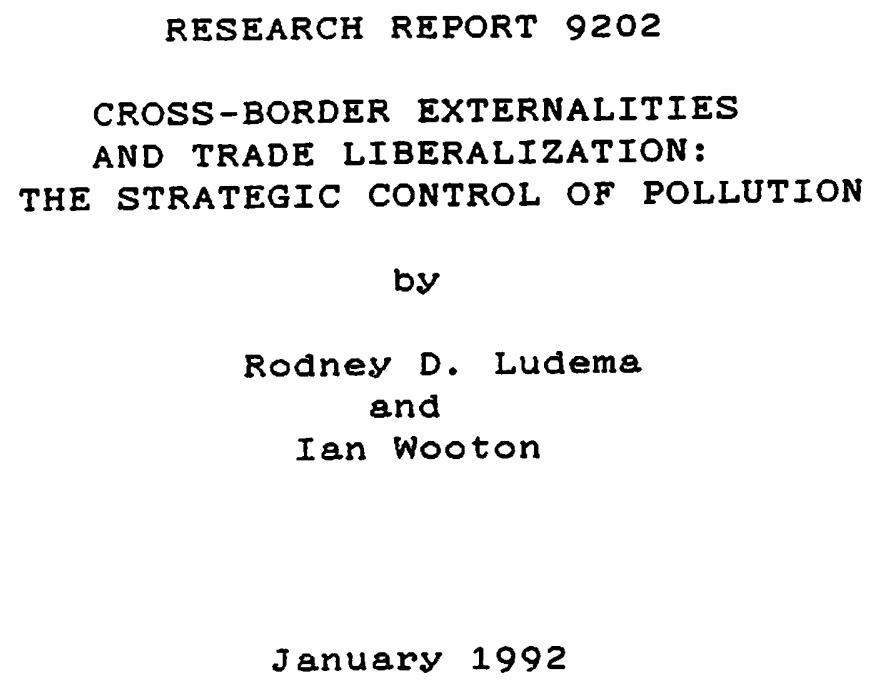




\title{
CROSS-BORDER EXTERNALITIES AND TRADE LIBERALIZATION: The Strategic Control of Pollution
}

\author{
Rodney D. Ludema
}

and

Ian Wooton*

Department of Economics, Social Science Centre

The University of Western Ontario

LONDON, Ontario N6A 5C2, Canada

* We are grateful to workshop participants at the University of Western Ontario for their comments and suggestions on an earlier draft of this paper. Particular thanks are due to John Chilton. Any remaining errors are entirely our responsibility. 


\section{INTRODUCTION}

A venerable topic in public finance theory is the question of the most appropriate intervention in a market characterized by negative externalities in production. [See, for example, Pigou (1932) and Baumol and Oates (1975).] The first-best policy is a tax on the externality itself or, if there are no means to reduce the level of the externality per unit of production (such as pollution abatement techniques), a tax on production will serve the same purpose. But there are circumstances in which the choices available to the social planner are circumscribed: the particular case that we address is when the good is traded internationally.

Suppose that an individual country produces a good whose production process results in a negative externality for the consumers in other countries, though neither the firms nor consumers (or their representatives) in the producing nation care about the externality. The globally optimal policy of a production or an externality tax cannot be directly implemented by the governments of the importing countries, as the firms are outwith their tax jurisdictions, and it will not be willingly imposed on the importers' behalf by the exporting nation. As a result, importers are reduced to finding some other (presumably sub-optimal) policy in order to limit the externality.

Of all the feasible policies available to the consuming countries' governments, a tariff on imports of the good produced by the offending country will be optimal. That is, no other feasible policy, including a uniform tariff, a domestic production subsidy, or a consumption tax will be superior to a discriminatory tariff, given this extraterritoriality [Markusen (1975a)]. This argument for a restriction on international trade is above and beyond the standard, beggar-thyneighbour terms-of-trade incentive for imposing tariffs. In fact, as long as a tariff can reduce the externality, there is monopoly power in trade.

Our specific interest in this problem was kindled by the negotiations on trade liberalization in North America, especially those for a trilateral North-American Free-Trade 
Agreement. ${ }^{1}$ The elimination of impediments to trade in certain commodities could result in greater output of externalities that are undesirable to residents in the importing countries. Examples of this might be: the more rapid depletion of temperate rain forests in Canada resulting from its increased sales of lumber to the US; the Acid Rain in Canada created by US manufacturing industries exporting to Canada; and the destruction of dolphins, trapped in the nets of Mexican fishers, exacerbated by liberalization of US imports of tuna from Mexico. This raises the question of whether multilateral free trade is an appropriate goal of international negotiations. Further, given the likelihood that bilateral and multilateral free-trade agreements are being reached, we ask what might be done to limit the increased environmental problems that might arise from trade liberalization. Environmental groups (particularly in the US) are very active in their lobbying against a comprehensive free-trade deal in the absence of a parallel agreement on environmental standards.

We look at the appropriate policies for the (socially planning) governments of both importing and exporting countries, both when the countries are free to impose taxes on trade and when they are constrained by a free-trade agreement. We focus on a two-country model, in order to rule out the possibility that any environmental standard might be circumvented by the simultaneous export of "dirty" goods (that is, those that generate large amounts of externality in their production) to some third country and the import of "clean" (that is, low externality) products from that nation. For ease of exposition, we shall occasionally refer to the externality as "pollution" or "emissions", though these terms are only relevant for specific examples of a more general problem. Our approach is to examine non-cooperative solutions to dealing with the pollution, and we assume that international transfers (to induce reduced trade barriers or promote pollution abatement) are not possible.

1 Specifically, our interest was sparked by a seminar given by John Whalley on his work in Uimonen and Whalley (1992). 
In Section 1, we consider the case in which the externality is produced in fixed proportions to output of the good. We demonstrate that, in the Nash equilibrium, both countries impose tariffs in an attempt to exploit their monopoly power in trade, but that the equilibrium tariff of the importing country will be higher than it would otherwise be as a result of the externality. When, in the Section 2, technology to abate the externality is introduced, we find that the exporting country will choose to impel their firms to adopt these techniques (or, in Section 3, the government decides to pay for their use) and thereby limit the output of the externality. This is not a magnanimous gesture to the citizens of the other country, but rather a means of capturing a larger share of the gains from trade. Thus while trade instruments can be used to pursue environmental goals, so too might environmental policy be used to gain an advantage in international trade. ${ }^{2}$

Section 4 looks at the outcome when a free-trade agreement (eliminating trade taxes) is reached between the two countries. Consequently the importing country, that cares about the externality, is unable (albeit indirectly) to limit its output. However, despite its own lack of concern, the exporter will tax the externality as this (again, indirectly) permits it to exploit its monopoly power of trade in the absence of an export tax. In Section 5, the environmental lobby's fears are assuaged by the introduction of a product standard. We examine the interaction of the externality tax and the product standard and show that, in the trading equilibrium, the product standard will always be binding. The paper concludes with a summary.

2 The focus on the terms-of-trade effects distinguishes our paper from other strategic models of environmental policy, for example, Markusen (1975b), Copeland (1989), and Conrad and Scott (1988). 


\section{A MOdel of TRADE WITH A Cross-Border Externality}

We adopt a very simple structure for the market for the good, $x .^{3}$ There are two countries, the home country, $H$, and the foreign country, $F$. All production is located in $F$, while all consumption takes place in $H$. Let $x$ be the quantity of the good that is produced and (in equilibrium) consumed. Demand for the good is a linear function of the domestic (that is, homecountry) consumer price, $p$. Hence the inverse demand curve is:

$$
p=a-b x .
$$

The good is produced in a perfectly competitive market. The foreign supply curve is linear in the producer price, $q$ :

$$
q=c+e x,
$$

where the domestic import price of $x$ is the producer price augmented by any (specific) export tax, $s$, (equivalent to a production tax, as there is no foreign consumption) and import tariff, $t$. Thus:

$$
p=q+t+s
$$

Let the production externality per unit of production be the fixed level $m^{4}$ That is, for each unit of the good that is produced, the marginal disutility from the creation of the externality is - $m$. This is assumed to be constant and hence the total cost (in terms of utility) from emissions of the externality amounts to $m x$. Home-country welfare is the sum of consumer surplus and tariff revenue less the externality. ${ }^{5}$ Thus, using equation (1), welfare in $H$ can be written as:

$$
u^{h}(x, t, m)=\frac{b x^{2}}{2}+(t-m) x
$$

3 While the model that we use is partial equilibrium, similar to that of Snape (1991), it may be readily extended to a 2-good, general equilibrium model.

4 We consider the possibility of pollution abatement technology in the next section.

5 In a political context, for example, Hillman and Ursprung (1991), the relationship between protectionist and environmentalist interests may be more complex. 
Foreign welfare is the sum of producer surplus and production-tax revenue and, using equation

(2), may therefore be written as:

$$
u^{f}(x, s)=\frac{e x^{2}}{2}+s x
$$

Equilibrium output can be determined by solving equations (1), (2), and (3) for $x$ :

$$
x=\frac{B}{b}\{A-(s+t)\},
$$

where $A \equiv(a-c)$ and $B \equiv b /(b+e)$.

Now consider the countries' choices of trade taxes. Let each country maximize national utility by setting its optimal tax rate, given the tax level of the other country. ${ }^{6}$ This yields the reaction functions of the two countries:

$$
\begin{aligned}
t^{h}(s, m) & =\frac{D(A-s)}{(1+D)}+\frac{m}{(1+D)} \\
s^{f}(t) & =\frac{B(A-t)}{(1+B)}
\end{aligned}
$$

where $D \equiv 1-B$. The Nash equilibrium is the solution of these simultaneous equations:

$$
\begin{aligned}
& t^{N}=\frac{D}{2}\{A-m\}+m, \\
& s^{N}=\frac{B}{2}\{A-m\} .
\end{aligned}
$$

The total (Nash-equilibrium) taxes on the good are:

$$
s^{N}+t^{N}=\frac{A+m}{2},
$$

6 As this is a partial equilibrium model, the two countries must use different instruments in the taxsetting game: $H$, the importer, uses a tariff; while $F$, the exporting nation, must use an export tax. Were the model recast in general equilibrium terms, as suggested in note 1 , the well known equivalence between export taxes and import tariffs would indicate that the outcome would be identical to that from a tariff war. 
while the Nash-equilibrium output is:

$$
x^{N}=\frac{B}{2 b}\{A-m\} .
$$

World welfare, $U$, which we define to be the sum of national welfare levels (that is, $u^{h}+u$ ) is maximized when aggregate trade taxes, $T^{*} E\left(s^{*}+t^{*}\right)$, equal to the size of the externality. That is, the global optimum is achieved when $T^{*}=m$. This forces the consumer to fully take into account the increased levels of emissions that would be associated with further purchases (and hence production) of the good. This level of trade taxes therefore achieves the standard closedeconomy optimum in which consumers are made to fully internalize the externality.

Now consider whether the global optimum will be achieved in the Nash equilibrium. The Nash-equilibrium aggregate tax level coincides with the optimum only when $A=m$ which, from equation (4), implies $x^{N}=0$. That is, except in the circumstance in which the tax wars result in autarky, and consequently production of neither the good itself nor the externality, the aggregate taxes on trade in the Nash equilibrium will exceed the globally optimal level.

These results are illustrated in Figure 1. In the absence of any externality (that is, $m=0$ ) the reaction curves for home and foreign countries are $t^{h}(s)$ and $s^{f}(t)$, respectively, with the Nash equilibrium occurring at $N(0)$. This outcome is purely a result of the familiar terms-of-trade argument for unilateral taxes on trade. The existence of an externality gives the government of $H$ an additional incentive to restrict trade, but has no direct effect on the actions of uncaring $F$. Consequently, $H^{\prime}$ s reaction curve shifts out and a new Nash equilibrium is attained at $N(m)$. The export tax declines while the import tariff increases, undoubtedly lowering welfare in $F$. The aggregate tax $T^{*}$ increases but, from equation (9), by less than the full amount of the externality. The presence of the externality results in a diminished volume of trade: as has been noted, a sufficiently large externality ( $m \geq A$ ) will lead to autarky. 


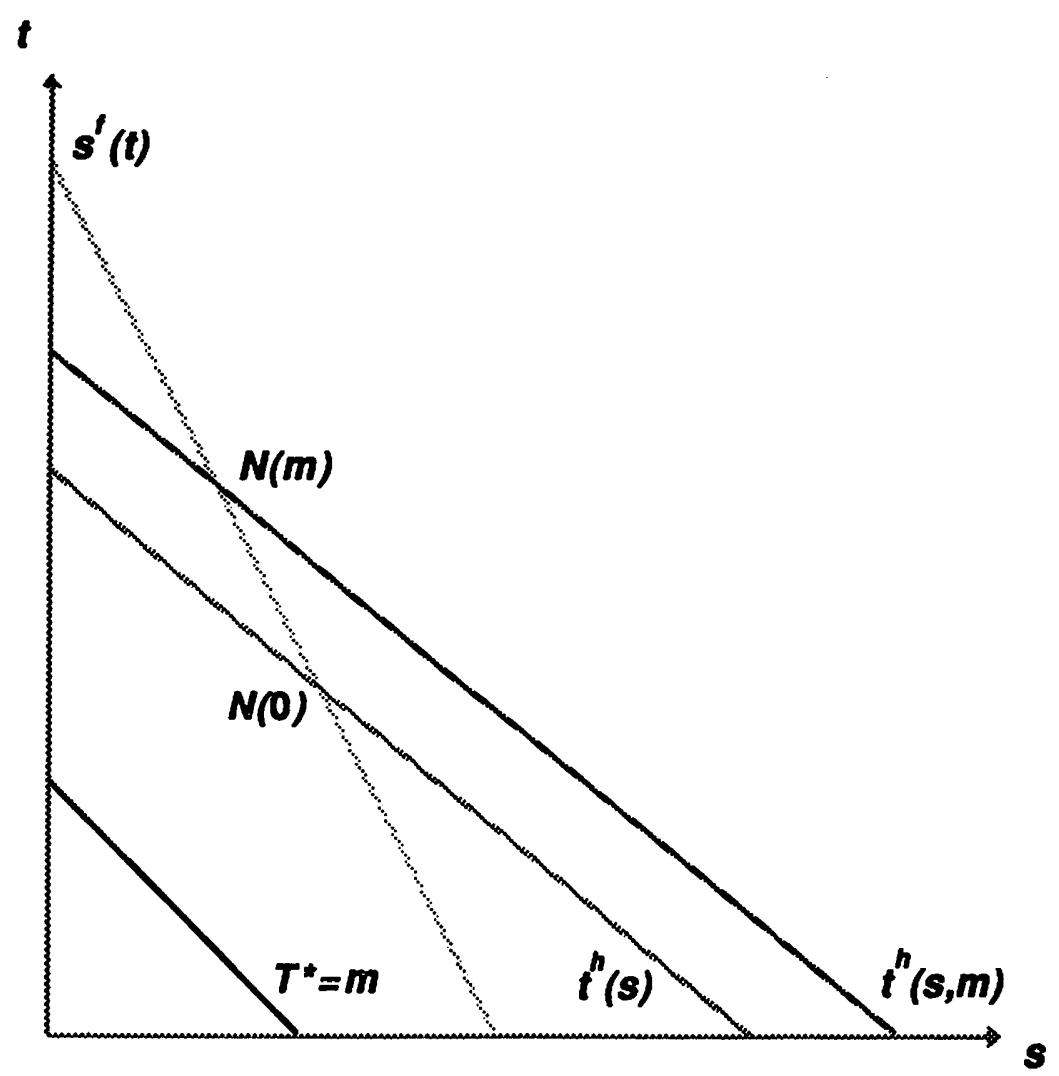

Figure 1

\section{EXTERNALITy Abatement TECHNOLOGy}

Now suppose that the externality produced per unit of the good can be reduced by abatement technology. Let the abatement per unit of production be $(m-\mu)$, where $\mu \leq m$ and suppose that the cost per unit of achieving this is $k(\mu)$, where $k(m)=0, k^{\prime} \leq 0, k^{\prime \prime} \geq 0$. A firm can be induced to reduce its rate of pollution either through a tax on the externality or by a subsidy on abatement costs. We consider the case of the tax in this section, leaving discussion of a subsidy to the next section.

7 While costs are increasing in the level of abatement $(m-\mu)$, they are linear in the quantity of the good produced, holding constant the emission rate, $\mu$. Thus we are assuming that there are no economies of scale in pollution abatement. 
We assume that tax/tariff game now takes on a two-stage timing structure. Specifically, let the foreign government choose its environmental policy prior to playing the trade-tax game with the home country. As is standard in games of this type, while the foreign country's externality tax is applied first, it is done so in full knowledge of the structure of the second stage of the game. 8

Let $\tau$ be a specific tax on a firm's production of the externality. At any level of output, firms choose $\mu$ so as to minimize $k(\mu)+\tau \mu$, the sum of the expenditure on pollution abatement and the tax on the remaining pollutants. ${ }^{9}$ We define $k(\tau)$ to be the minimum costs associated with the pollution tax, that is $k(\tau) \equiv \min \{k(\mu)+\tau \mu\}$, and $\mu(\tau)$ to be the firm's cost-minimizing level of emissions, where $k^{\prime}(\mu)=-\tau$. Hence the private marginal cost of the firm is augmented by $K(\tau)$. Domestic demand is not directly affected by this foreign policy and continues to be represented by equation (1). However, the foreign supply curve shifts back due to the additional marginal costs in production:

$$
q=c+\kappa(\tau)+e x .
$$

Consumer and producer prices continue to differ by the size of the trade taxes, as in equation (3). Welfare in $H$ now depends on the actual emission level that is achieved:

$$
u^{h}(x, t, \tau)=\frac{b x^{2}}{2}+\{t-\mu(\tau)\} x
$$

8 This sequence of policy decisions might be justified on the basis that a pollution tax involves investment by the producers in abatement equipment; and hence their response to such $a$ tax is "slower" than to production taxes (the export tax and the tariff).

9 We assume that taxes and tariffs must be applied uniformly across firms to rule out the possibility of a firm strategically setting $\mu$. 
9

Foreign welfare now has an additional component, the revenue from the externality tax. Recognizing that the externality is now a function of country $F^{\prime}$ s pollution tax, national welfare can be written:

$$
u^{f}(x, s, \tau)=\frac{e x^{2}}{2}+[s+\tau \mu(\tau)] x
$$

Equilibrium output is the solution to equations (1), (11), and (3):

$$
x=\frac{B}{b}\{\Gamma(\tau)-(s+t)\}
$$

where $B$ is as previously defined, while $\Gamma(\tau) \equiv\{a-c-\kappa(\tau)\}$. Comparing equations (6) and (14), we see that, for the same level of aggregate trade taxes, the introduction of an externality tax has lowered output. ${ }^{10}$

The reaction functions become:

$$
\begin{aligned}
& t^{h}(s)=\frac{D\{\Gamma(\tau)-s\}}{(1+D)}+\frac{\mu(\tau)}{(1+D)}, \\
& s^{f}(t)=\frac{B\{\Gamma(\tau)-t\}}{(1+B)}-\frac{\tau \mu(\tau)}{(1+B)} .
\end{aligned}
$$

Finding the Nash equilibrium:

$$
\begin{aligned}
& t^{N}=\frac{D}{2}\{\Gamma(\tau)-(1-\tau) \mu(\tau)\}+\mu(\tau), \\
& s^{N}=\frac{B}{2}\{\Gamma(\tau)-(1-\tau) \mu(\tau)\}-\tau \mu(\tau) .
\end{aligned}
$$

The aggregate (Nash) taxes on trade are:

$$
s^{N}+t^{N}=\frac{\Gamma(\tau)+(1-\tau) \mu(\tau)}{2}
$$

10 In terms of the "mechanics" of the model, $A$, the difference between the intercepts of the demand and supply curves, is reduced by the per-unit cost of externality abatement, $k(\tau)$, to yield $\Gamma(\tau)$. 
and the Nash-equilibrium output is:

$$
x^{N}=\frac{B}{2 b}\{\Gamma(\tau)-(1-\tau) \mu(\tau)\}
$$

Now substitute this into equation (13) and differentiate in order to determine the foreign government's optimal externality tax. Simplifying, using equation (16), yields:

$$
\frac{d u^{f}}{d \tau}=\frac{2 b+e}{b+e} \frac{k^{\prime}(\mu)+1}{k^{\prime \prime}(\mu)} x^{N}
$$

This expression has critical values at $k^{\prime \prime}=\infty$ and at $\tau^{*}=1$. Thus in the Nash trade-tax game, the foreign country will have set an externality tax of unity, forcing the producing firms to fully internalize the pollution. ${ }^{11}$

In order to understand this outcome, consider the foreign government's behaviour in the second stage of the game. The externality tax has had two effects: the first is in having induced firms to spend resources on emission control; while the second effect is that the private marginal costs of production have been raised through the penalization of production of the remaining pollution. This latter outcome means that the externality tax acts in large part as a production tax which, in the model in question, is identical to an export tax. So in the second stage of the game, in which $\mu$ is set and the abatement expense, $k(\mu)$, is a sunk cost, $\tau$ and $s$ are perfect substitutes: the "effective" export tax being $s+\tau \mu$. This implies that the foreign government can pre-commit $\tau$ to any level that it wishes in the first stage of the game, while $s$ can be chosen bring the effective tax to its optimal level. This same reasoning implies that the foreign government has no incentive to change $\tau$ ex post. Thus $\tau^{*}$ is a time-consistent policy.

11 Note that $\tau^{*}=1$ is the rate of taxation that is socially optimal in free trade (that is, when $t=s=0$ ). However, as we shall show in a later section, when there is free trade, $\tau^{*}$ the optimal pollution tax from the perspective of the foreign government will not coincide with the socially optimal rate. 
Why does $F$ use a combination of direct export taxation and a tax on the externality? As has been shown above, the existence of the externality makes the home country more aggressive in its tariff-setting behaviour. The externality tax has the advantage over the export tax of lowering $\mu$, and thereby moderating the home country's trade tax. ${ }^{12}$

\section{A SUbSIDY ON ABATEMENT}

In this section we consider the case in which the government reimburses firms for their externality expenditures. So, by setting the subsidy per unit $\sigma=k(\mu)$, the foreign government effectively chooses the level of externality per unit of production $\mu(\sigma)$, but it will not affect the firms' marginal costs and hence the supply curve of the good will not shift. Ordinarily this would imply that the subsidy to pollution abatement is not equivalent to the pollution tax. However, in the presence of the second-stage tax/tariff game, we shall establish that they are indeed equivalent.

National welfare must take into account the production of the externality and the cost of the pollution abatement activity:

$$
\begin{gathered}
u^{h}(x, t, \sigma)=\frac{b x^{2}}{2}+\{t-\mu(\sigma)\} x, \\
u^{f}(x, s)=\frac{e x^{2}}{2}+(s-\sigma) x .
\end{gathered}
$$

Equilibrium output is again determined from equations (1), (2), and (3), hence $x$ is as in equation (6); while the reaction functions are:

$$
\begin{aligned}
& t^{h}(s)=\frac{D(A-s)}{(1+D)}+\frac{\mu(\sigma)}{(1+D)} \\
& s^{f}(t)=\frac{B(A-t)}{(1+B)}+\frac{\sigma}{(1+B)}
\end{aligned}
$$

12 This is similar to the strategic enhancement of the environment discussed in Copeland (1989). 
The Nash equilibrium tariffs are:

$$
\begin{aligned}
& t^{N}=\frac{D}{2}\{A-\sigma-\mu(\sigma)\}+\mu(\sigma), \\
& s^{N}=\frac{B}{2}\{A-\sigma-\mu(\sigma)\}+\sigma .
\end{aligned}
$$

Aggregate trade taxes in the Nash equilibrium are:

$$
s^{N}+t^{N}=\frac{A+\sigma+\mu(\sigma)}{2},
$$

and the Nash-equilibrium output is:

$$
x^{N}=\frac{B}{2 b}\{A-\sigma-\mu(\sigma)\} .
$$

Now determine the optimal subsidy. Differentiating foreign welfare [equation (21)] with respect to the subsidy rate yields:

$$
\begin{gathered}
\frac{d u^{f}}{d \sigma}=(2 b+e) x^{N} \frac{d x^{N}}{d \sigma} \\
\text { where } \frac{d x^{N}}{d \sigma}=-\frac{B}{2 b}\left(1+\frac{d \mu}{d \sigma}\right)=0
\end{gathered}
$$

This has exactly the same outcome as in the externality-tax example. To see that this is the case, compare the Nash-equilibrium output levels for the subsidy on abatement [equation (25)] with those for an externality tax [equation (18)]. Note that $\Gamma(\tau)+\tau \mu(\tau)=A-k(\mu)$. If these abatement costs were instead covered by a subsidy, that is, $k(\mu)=\sigma$; then the two equations coincide. As both output and the level of emissions are identical in the two cases, so too are the welfare levels of the countries. Thus a pollution tax, $\tau$, and a subsidy on abatement, $\sigma$, that induce the same level of emissions, $\mu$, will generate identical trade-tax-setting behaviour. Hence the optimal subsidy must reduce emissions by the same amount as a hundred-per-cent tax rate would. ${ }^{13}$

13 In the case of the pollution tax, $\tau^{*}=1$, and for the subsidy, $\tau^{*}=0$, with the same expense on pollution control and the identical effective export tax. Hence the outcomes are identical. 


\section{EXTERNALITy TAXes WITH a Free-Trade AgreEMENT}

Now restrict the import tariff and export tax to zero, as would be required by a free-trade agreement. The only instrument available is the externality tax of the foreign government. In such a case: equation (1) represents demand; equation (11) represents supply; while consumer and producer prices are equated, that is:

$$
p=q
$$

Home and foreign welfare are (respectively):

$$
\begin{aligned}
& u^{h}(x, \tau)=\frac{b x^{2}}{2}-\mu(\tau) x \\
& u^{f}(x, \tau)=\frac{e x^{2}}{2}+\tau \mu(\tau) x .
\end{aligned}
$$

Equilibrium output is determined from the solution of equations (1), (11), and (27):

$$
x=\frac{B}{b} \Gamma(\tau) .
$$

Maximizing foreign welfare through the choice of the optimal externality tax yields an implicit expression for $\tau^{*}$ :

$$
\tau^{*} \mu^{*}=\frac{\left[B-\rho\left(\tau^{*}\right)\right]\left[A-k\left(\mu^{*}\right)\right]}{1+B-\rho\left(\tau^{*}\right)}
$$

where $\mu^{*} \equiv \mu\left(\tau^{*}\right)$ and $\rho(\tau)$ is the elasticity of response in abatement level $\mu$ with respect to changes in the rate of externality tax $\tau$, that is:

$$
\rho(\tau)=-\frac{\tau}{\mu(\tau)} \mu^{\prime}(\tau) .
$$


Two points can be made here. First, $\tau^{*}$ does not generally coincide with the (globally) socially optimal level of tax $\left(\tau^{*}=1\right)$. This is because the foreign country is not imposing the externality tax in order to quell the production of a noxious substance (or the like), but is doing so for the purely selfish motive of exploiting its monopoly power in trade. Second, $\tau \mu(\tau)$ is the effective export tax arising from the use of the externality tax. The optimal level of this [from equation (31)] is lower than the export tax that the foreign country would unilaterally impose:

$$
\left.s\right|_{t=0}=\frac{B A}{(1+D)}
$$

if it were not constrained from doing so. The first-best policy for a country that wishes to manipulate its terms of trade is, of a course, the tariff. As such an instrument is unavailable, because of the free-trade agreement, the externality tax is the second-best policy. It is inferior to the tariff in that it induces firms to spend resources on pollution abatement (a worthless, but costly, activity to the citizens of $F$ ) and so the externality tax will be imposed at a lower effective level than that of the optimal tariff.

\section{EFfects of a Home-Country Product Standard}

The outcome so far for the home country is that, under a free-trade agreement, it has lost any influence over the level of the externality, through relinquishing its import tariff, as well as having no means of retaliating against the behaviour of the foreign country. Thus the free-trade agreement would likely be opposed both by protectionists and the environmental lobby. Consider another policy, in the context of a free-trade agreement, that appears designed to assuage the fears of the latter group, and may go a long way to satisfying the first as well: a product standard imposed by the home country on goods sold on its domestic markets. 
Let this product standard takes the form of an upper bound on the level of externality produced per unit of the good manufactured. We assume that the government of $\mathrm{H}$ can determine which products exceed this limit and prevent them from entering the country, while goods that satisfy the standard are imported without further restriction. Let $\varepsilon$ denote the product standard, in which commodities meeting this standard involve per-unit production of the externality that is no greater than this limit. The product standard will be ineffective if it exceeds $m$, the pollution level of firms that take no abatement measures. If the standard is binding, firms will reduce their emissions rate to $\varepsilon$ and incur the additional per-unit cost $k(\varepsilon)$, provided that the marginal cost $c+k(\varepsilon)$ of production does not exceed the market price. Hence, as long as $a-c-k(\varepsilon)>0$, there will be trade.

If the foreign country has access to an externality tax, then product standards above $\mu^{*}$ will not be binding. This is because the unconstrained optimal externality tax $\tau^{*}$ induces firms to choose $\mu^{*}$, which more than satisfies the product standard. This is represented by point $\mathbf{A}$ in Figure 2. Hence, if we let $\tau(\varepsilon)$ denote the best response of the foreign country to product standard $\varepsilon$, then $\tau(\varepsilon)=\tau^{*}$, for all $\varepsilon \geq \mu^{*}$. In other words, when the home country introduces an ineffectual policy, $F$ 's best response is to ignore it and continue to follow what continues to be its optimal tax policy.

For product standards tighter than $\mu^{*}$, that is, $\varepsilon<\mu^{*}$, there are two possibilities. Either the foreign country can choose an externality tax that will induce exactly the same level of $\mu$ as $\varepsilon$, or it can choose an externality tax that will not have any effect upon firms' choices of $\mu$. If it does the former, it chooses $\tau(\varepsilon)$ so that $\mu(\tau(\varepsilon))=\varepsilon$. Letting $\mu^{-1}(\varepsilon)$ be the inverse of $\mu(\tau)$, gives:

$$
\tau(\varepsilon)=\mu^{-1}(\varepsilon) .
$$

Such a choice is represented by point B in Figure 2. 


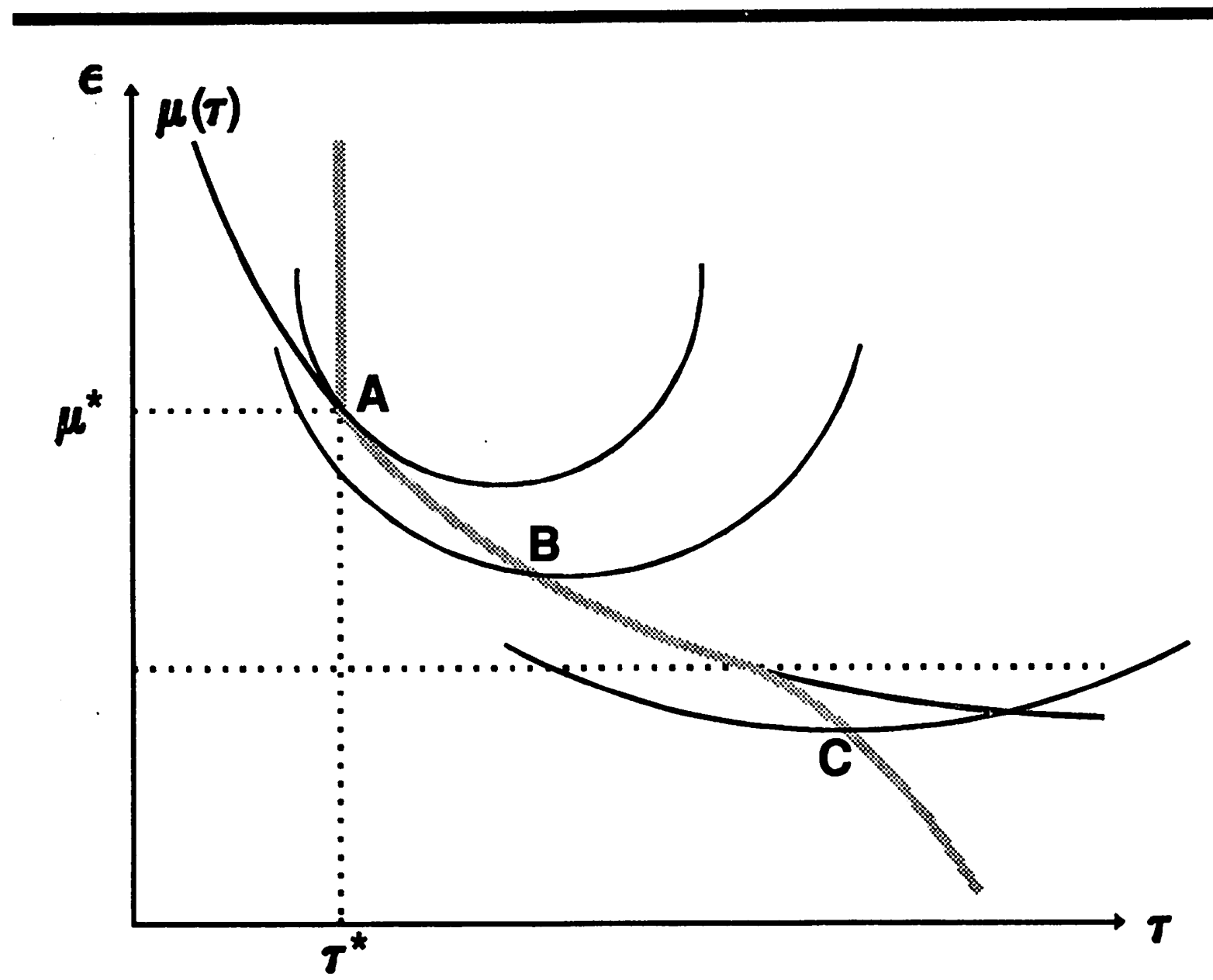

Figure 2

If $F$ chooses its tax so that it has no effect on firms' choices of $\mu$, it is essentially using the externality tax solely as a trade-policy instrument. Its optimal choice, in this case, is to set $\tau$ such that $\tau \varepsilon$ is equal to its optimal export tax. This gives:

$$
\tau(\varepsilon)=\frac{B[A-k(\varepsilon)]}{\varepsilon(1+B)}>0, \text { for } x \geq 0,
$$

which is represented by point $\mathbf{C}$ in Figure 2.

It is clear that for $\varepsilon<\mu^{*}$ (but not too small), $F$ will choose to follow (34) over (35). As $\varepsilon$ approaches $\mu^{*}, \mu^{-1}(\varepsilon)$ becomes arbitrarily close to $\tau^{*}$; whereas the expression in (35) does not, as long as $\rho^{*}>0$. Given the continuity of the welfare functions, this implies that for some (perhaps 
small) range of product standards, $F$ will choose a tax that induces exactly the standard imposed by $H$.

The best-response externality tax of $F$ is therefore represented by the three line segments shown in Figure 3 as $t$.

The home government chooses its optimal product standard given the externality tax set by the foreign government. A binding product standard will always be chosen. To see this, suppose that the government of $H$ were contemplating setting $\varepsilon=\mu(\tau)$ as a best response to $\tau$, where $\mu(\tau)$, as before, is the firms' cost-minimizing choice. The home government cannot gain by raising $\varepsilon$ above $\mu(\tau)$, as the product standard would not bind. But the home government can gain by lowering $\varepsilon$ below $\mu(\tau)$. For a binding product standard, home welfare is given by:

where:

$$
u^{h}(x, \varepsilon)=\frac{b}{2} x^{2}-\varepsilon x,
$$

$$
x=\frac{B}{b}\{A-[k(\varepsilon)+\tau \varepsilon]\} .
$$

Differentiating equation (36) yields:

$$
\frac{\partial u^{h}}{\partial \mu}=(b x-\varepsilon) \frac{\partial x}{\partial \mu}-x .
$$

Now, $\frac{\partial x}{\partial \varepsilon}=0$, when evaluated at $\varepsilon=\mu(\tau)$. Thus, as long as there is trade (that is, $x>0$ ), $H$ can gain by tightening its product standard such that it binds. ${ }^{14}$

For $\varepsilon<\mu(\tau)$, the first-order condition for maximization of home welfare is given implicitly by:

$$
\varepsilon=\left[B+\frac{1}{k^{\prime}(\varepsilon)+\tau}\right]\{A-[k(\varepsilon)+\tau \varepsilon]\}>0, \text { for } x \geq 0 .
$$

The home-country's best-response product standard satisfies equation (38), and is shown on Figure 3 as the locus $\varepsilon^{h}$.

14 The magnitude of the gain from lowering $\varepsilon$ for a given $x$ is of the first order, whereas the loss from the decline in $x$, given $\varepsilon$ near $\mu(\tau)$, is of the second order. 


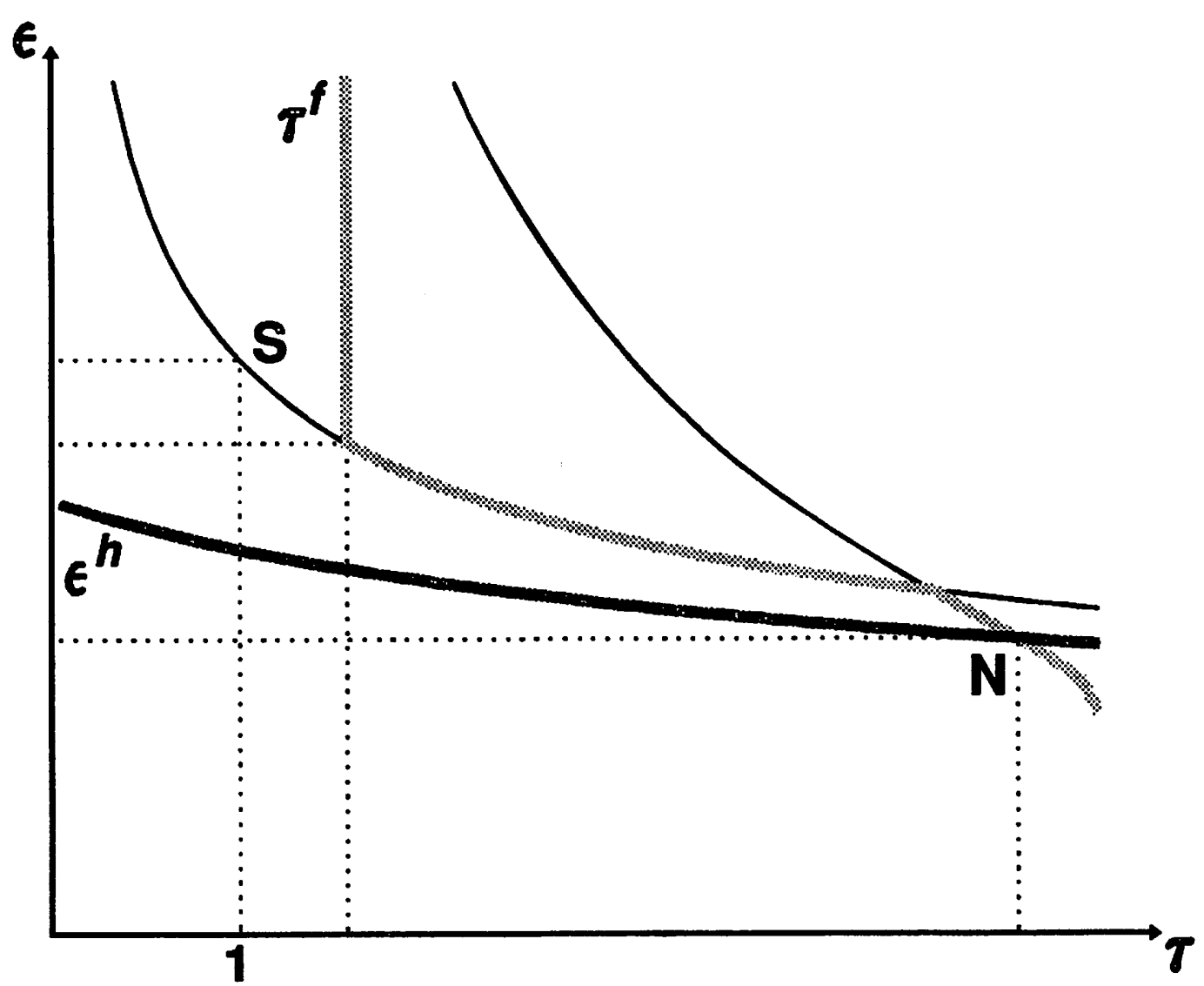

Figure 3

The Nash equilibrium is at the intersection of $\tau^{f}$ and $\varepsilon^{h}$, and is labelled $\mathbf{N}$ in the diagram. It can be shown that the Nash equilibrium externality tax is strictly greater than the socially optimal rate (of unity), labelled $S$ in the diagram. Thus we have the somewhat ironic result that competition between countries in controlling emissions leads to more restrictive measures than they would choose cooperatively.

\section{SUMMARY AND CONCLUSIONS}

We have shown that, in a non-cooperative setting, international trade restrictions may be used as instruments of environmental policy and also that the reverse is true, that pollution taxes and emission controls will be used in order to exploit monopoly power in trade. Thus the formation 
of a free-trade area may not bring about the efficiency gains of unrestricted trade that would arise in the absence of the externality.

This has some relevance for the question as to why free-trade agreements are made in the first place. Without pollution and in the absence of international transfers, there is nothing to guarantee that a move to free trade will be Pareto improving, as the international distribution of gains between the nations may well be asymmetric, such that some countries lose from the trade liberalization. Nevertheless, it is often argued in policy circles that the costs of concessions made by an individual country in lowering its import barriers may well be more than compensated by the benefits from the reciprocal tariff reductions made by its trading partners, such that each country gains without the need to implement international transfers. The more similar are the countries, in terms of their size and stage of development, the stronger this argument: in that bilateral trade flows will be closely balanced and the terms-of-trade effects will be quantitatively close.

When countries markedly differ in size or development, the gains from bilateral trade liberalization will, in all likelihood, be quite asymmetrically distributed: the smaller country benefitting both from eliminating its own trade barriers and from the concessions made by its much larger trading partner, while the latter gives up the exercise of its monopoly power with little in return. In the absence of international transfers, it then seems unlikely that large, developed countries would be inclined (on purely economic grounds) to form free-trade agreements with smaller countries. However, were a small country's production activities the source of a negative externality, then it has something to offer its larger trading partner in order to induce it into a free-trade agreement, namely measures to restrict pollution.

We end with a cautionary note. It is quite legitimate for the environmental lobby to argue that pollution policies must be part of free-trade negotiations. But one should question the motives of the nation that freely offers to clean up its act: its may be up to dirty tricks. 


\section{REFERENCES}

Baumol, William J. and Wallace E. Oates, The Theory of Environmental Policy, Englewood Cliffs, NJ: Prentice Hall, 1975.

Copeland, Brian, "Strategic Enhancement and Destruction of Fisheries and the Environment in the Presence of International Externalities," Discussion Paper No. 89-12, University of British Columbia, 1989.

Conrad, Jon M. and Anthony D. Scott, "Transfrontier Pollution: Cooperative and Noncooperative Solutions," Discussion Paper No. 88-30, University of British Columbia, 1988.

Hillman, Ayre L. and Heinrich Ursprung, "The Influence of Environmental Concerns on the Political Determination of International Trade Policy," in Kym Anderson and Richard Blackhurst, eds., The Greening of World Trade Issues, New York: Harvester-Wheatsheaf, 1991, forthcoming.

Markusen, James R., (1975a) "International Externalities and Optimal Tax Structures," Journal of International Economics, 1975, 5, 15-29.

, (1975b) "Cooperative Control of International Pollution and Common

Property Resources," Quarterly Journal of Economics, November 1975, 89, 618-632.

Pigou, A. C., The Economics of Welfare, London: Macmillan, 1932.

Snape, Richard, "The Environment, International Trade, and Competitiveness," in Kym Anderson and Richard Blackhurst, eds., The Greening of World Trade Issues, New York: Harvester-Wheatsheaf, 1991, forthcoming.

Uimonen, Peter and John Whalley, Trade and Environment, Washington, DC: Institute for International Economics, 1992, forthcoming. 